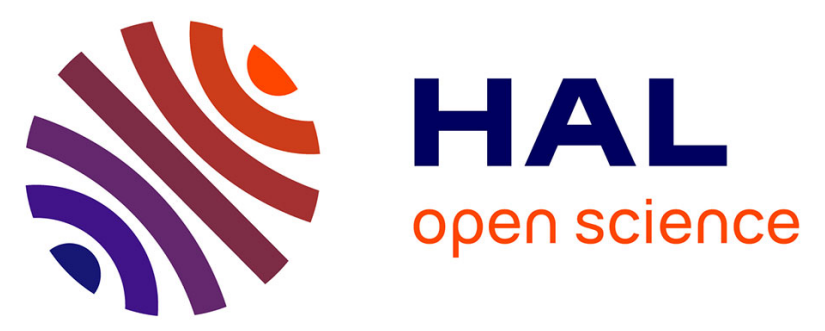

\title{
Multi-omics profiling reveals that eating difficulties developed consecutively to artificial nutrition in the neonatal period are associated to specific saliva composition
}

\author{
Martine Morzel, Eric Neyraud, Hélène Brignot, Patrick Ducoroy, Aline \\ Jeannin, Géraldine Lucchi, Caroline Truntzer, Cécile Canlet, Marie \\ Tremblay-Franco, Christophe Hirtz, et al.
}

\section{- To cite this version:}

Martine Morzel, Eric Neyraud, Hélène Brignot, Patrick Ducoroy, Aline Jeannin, et al.. Multi-omics profiling reveals that eating difficulties developed consecutively to artificial nutrition in the neonatal period are associated to specific saliva composition. Journal of Proteomics, 2015, 128, pp.105-112. 10.1016/j.jprot.2015.07.028 . hal-01216253v2

HAL Id: hal-01216253

https://hal.science/hal-01216253v2

Submitted on 26 Oct 2015

HAL is a multi-disciplinary open access archive for the deposit and dissemination of scientific research documents, whether they are published or not. The documents may come from teaching and research institutions in France or abroad, or from public or private research centers.
L'archive ouverte pluridisciplinaire HAL, est destinée au dépôt et à la diffusion de documents scientifiques de niveau recherche, publiés ou non, émanant des établissements d'enseignement et de recherche français ou étrangers, des laboratoires publics ou privés. 


\title{
Multi-omics profiling reveals that eating difficulties developed consecutively to artificial nutrition in the neonatal period are associated to specific saliva composition
}

\author{
Martine Morzel $^{\text {a,b,c,* }}$, Eric Neyraud ${ }^{\text {a,b,c }}$, Hélène Brignot ${ }^{\text {a,b,c }}$, Patrick Ducoroy ${ }^{\mathrm{d}}$, Aline Jeannin ${ }^{\mathrm{d}}$, \\ Géraldine Lucchi $^{\mathrm{d}}$, Caroline Truntzer ${ }^{\mathrm{d}}$, Cécile Canlet ${ }^{\mathrm{e}}$, Marie Tremblay-Franco ${ }^{\mathrm{e}}$, Christophe Hirtz ${ }^{\mathrm{f}}$, \\ Ségolène Gaillard ${ }^{\mathrm{g}}$, Noël Peretti ${ }^{\mathrm{h}}$, Gilles Feron ${ }^{\mathrm{a}, \mathrm{b}, \mathrm{c}}$ \\ a CNRS, UMR6265 Centre des Sciences du Goût et de l'Alimentation, F-21000 Dijon, France \\ b INRA, UMR1324 Centre des Sciences du Goût et de l'Alimentation, F-21000 Dijon, France \\ ' Université de Bourgogne, UMR Centre des Sciences du Goût et de l'Alimentation, F-21000 Dijon, France \\ d IFR 100 Santé-STIC, CLIPP (Clinical and Innovation Proteomic Platform), F-21000 Dijon, France \\ e INRA, UMR 1331 TOXALIM, Research Centre in Food Toxicology, F-31027 Toulouse, France \\ ${ }^{\mathrm{f}}$ CHU Montpellier, Institute of Research in Biotherapy, Hôpital Saint Eloi, Laboratory of Biochemistry and Clinical Proteomics, INSERM U1040, F-34000 Montpellier France \\ g INSERM, CIC 1407, Hospices Civils de Lyon, CNRS, UMR5558, Université de Lyon, F-69000 Lyon, France \\ h Université de Lyon, Claude Bernard Lyon 1, Faculté de Médecine Lyon-Est, INSERM U1060, CarMeN laboratory, Hospices Civils de Lyon, F-69003 Lyon, France
}

\section{A R T I C L E I N F O}

Article history:

Received 9 June 2015

Received in revised form 6 July 2015

Accepted 23 July 2015

Available online 29 July 2015

\section{Keywords:}

Saliva

Profiling

Children

Feeding difficulties

Tube feeding

\begin{abstract}
A B S T R A C T
Prolonged enteral or parenteral nutrition in neonatal periods sometimes results in eating difficulties persisting for years, with reduced food intake through the oral route and thereby reduced stimulation of the oral cavity. Aiming at describing the consequences on oral physiology, saliva of 21 children with eating difficulties (ED) was compared to that of 23 healthy controls, using various omics and targeted methods. Overall, despite heterogeneity within the groups (age, medication etc.), the three spectral methods (MALDI-TOF, SELDI-TOF, ${ }^{1} \mathrm{H}$ NMR) allowed discriminating ED and controls, confirming that oral stimulation by food intake plays a role in shaping the composition of saliva. Saliva of ED patients exhibited a lower antioxidant status and lower levels of the salivary protease inhibitors cystatins. Other discriminant features (IgA1, dimethylamine) may relate to modified oral and/or intestinal microbial ecology. Finally, salivary profiles of ED patients were partly comparable to those of subjects with exacerbated gustatory sensitivities, in particular with reduced abundance of cystatin SN and higher abundance of zinc-alpha-2-glycoprotein. Whether this translates taste hypersensitivity and contributes to the eating difficulties deserves further attention.
\end{abstract}

(c) 2015 Elsevier B.V. All rights reserved.

\section{Introduction}

Enteral nutrition through a nasogastric tube or a gastrotomy, or even total parenteral nutrition, is sometimes required as part of pediatric medical care. Tube feeding is for example used in premature babies who have not fully developed feeding skills, in particular appropriate coordination of sucking/swallowing and breathing or muscular strength and coordination to ensure safe swallowing [1]. Artificial nutrition can also be needed in children affected by a variety of medical conditions (e.g. heart disease, renal failure, intestinal malabsorption...) while they are receiving medical treatment. Although tube feeding has some obvious and immediate benefits from a nutrition point of view, some children develop feeding difficulties when weaning from the tube is

* Corresponding author at: CNRS, UMR6265 Centre des Sciences du Goût et de l'Alimentation, F-21000 Dijon, France.

E-mail address: Martine.Morzel@dijon.inra.fr (M. Morzel). attempted. For example, the case of 9 infants aged 3-14 months, who had never received oral feeding since birth was reported. Regardless of confounding comorbidities, it was described that most of those infants had an exacerbated gag reflex and deficient sucking abilities [2]. The authors also suggested that the time necessary to resume full oral feeding increased with the duration of tube feeding. This was confirmed by another study [3] which compared the feeding skills at 11 and 17 months corrected age of pre-term vs full-term infants. Preterm infants who had received nasogastric feeding for more than 3 weeks exhibited an increased oral sensitivity (translated for example by facial defensive behavior to approaching contact with the lips and mouth) and delayed feeding development in comparison to full-term infants but also compared to pre-term infants who had received nasogastric feeding for less than two weeks. This study also evidenced that feeding difficulties can persist for prolonged periods. Similarly, in a review of 100 infants fed by nasogastric and gastrotomy tubes within their first 6 months of life, the transition from tube to oral feeding was 
extremely lengthy or even impossible in three years of time in a small proportion (6\%) of children [4]. Altogether, tube feeding in the neonatal period, especially when it is prolonged and associated to medical complications, may sometimes result in the need of constant or intermittent nutritional support for years. This has for consequences reduced food intake through the oral route and lower sensory stimulation of the oral cavity.

Sensory stimulation of the oral cavity is known to affect salivary flow and composition. In particular, taste and trigeminal stimulations have an immediate effect on saliva flow [5-7], and the composition in proteins has also been reported to be modified by exposure to compounds eliciting a taste or trigeminal sensation [8-11]. Besides this reflex response, the plasticity of saliva composition according to diet has been suggested. For example, in a 1970 review considering both animal and human studies [12], the consistency (liquid vs solid) of nutritionally equivalent meals was reported to have an impact on saliva flow which highlights the importance of mechanical stimulation of the oral cavity on salivary glands' secretion. In addition, salivary parameters may also be linked to sensory acceptance of foods in humans, as suggested by the positive associations between saliva composition and fat liking [13] or between salivary protein profiles and acceptance of bitterness in infants [14].

The present study focuses on children who have received artificial nutrition in their neonatal period and who have developed long-term feeding difficulties resulting in limited amount of energy intake through the oral route. Given this reduced stimulation of the oral cavity, and the role that saliva may play in ingestive behavior, this proof-of-concept study aimed at describing the consequences of such diets on saliva composition. Complementary "omics" methods covering a range of expression products (proteins, peptides, metabolites) were used, as well as targeted methods (protein content, enzymatic activities, antioxidant status).

\section{Materials and methods}

\subsection{Study subjects}

The study was approved by the local ethical committee (Comité de Protection des Personnes Sud-Est II, $n^{\circ}$ 2011-039-2) and by the Direction Générale de la Santé (AFFSAPS, $n^{\circ}$ B111079-90). Written informed consent was obtained from the children's parents. The study included 21 children ( 12 females, 9 males) who had developed eating difficulties consecutively to receiving artificial nutrition in the neonatal period. More specifically, the criterion of inclusion was that patients had received nutritional support for at least 3 months within the 6 months period following birth. At the time of sampling, the patients were aged between 22 and 89 months (median value 4.8 years) and were still fed via the enteral or parenteral route to a minimum level of $50 \%$ of their total energy intake. Dental examinations revealed that three patients displayed tartar build-ups. The study also included 23 healthy children (11 females, 12 males) aged between 22 and 136 months (median value 5.3 years) as controls. No abnormalities were detected with regards to their dental status. The two groups were age-matched by age classes ( up to 5 year-old, 6-11 year-old). Patients with eating difficulties are designated below as "ED" and healthy controls as " $C$ ".

\subsection{Saliva sampling}

Saliva was sampled at the time of inclusion (T0), and again 6 months (T6) and 12 months (T12) afterwards. Sampling was performed by aspiration of saliva on the floor of the mouth through a soft catheter. Saliva was collected in a plastic tube placed on ice. Aspiration lasted for $5 \mathrm{~min}$, or for a shorter period in case of discomfort. Within $30 \mathrm{~min}$ after sampling, saliva was centrifuged at $10,000 \mathrm{~g}$ for $15 \mathrm{~min}$ at $4{ }^{\circ} \mathrm{C}$ and the supernatant was aliquoted. Aliquots were stored at $-80^{\circ} \mathrm{C}$ until analyses.

\subsection{Targeted biochemical analyses}

All enzyme activities were expressed in milli International Enzyme Activity Units (IU) per $\mathrm{ml}$ of saliva. One IU is defined as the amount of enzyme that catalyzes the conversion of $1 \mu \mathrm{mol}$ of substrate per minute. Protein concentration (mg.ml ${ }^{-1}$ ) was measured with a Quick Start Bradford protein assay (Bio-Rad, France) with bovine serum albumin as the calibration standard.

\subsubsection{Amylolysis}

Amylase activity was determined using the amylase CNPG3 assay kit (Biolabo France). 2-chloro-4-nitrophenyl malto trioside (CNPG3) is converted in CNP (Chloro-nitro-phenol) by salivary amylase during incubation with saliva samples at $37^{\circ} \mathrm{C}$. Kinetics of absorbance at $405 \mathrm{~nm}$ was performed at $37^{\circ} \mathrm{C}$ using a microplate spectrophotometer (Victor $3-\mathrm{V}$, PerkinElmer, France). The initial rate of reaction is compared to a standard to determine samples amylase activity. The standard curve was established using quality control serum Extratol-N (Biolabo).

\subsubsection{Lipolysis}

Lipolysis was adapted from the method described in Neyraud et al. [13]. A $20 \mathrm{mM}$ substrate solution was prepared from 4methylumbelliferyl-7-oleate (Sigma-Aldrich, France) in ethanol, and it was diluted to $1 \mathrm{mM}$ in a buffer containing $20 \mathrm{mM}$ Tris- $\mathrm{HCl}$, pH 7.5, 4 mM CaCl2, 2 mM EDTA, 0.2\% (w/v) NaTDC (sodium taurodeoxycholate), $1 \mathrm{mM}$ PMSF (phenylmethylsulphonyl fluoride), $1 \mathrm{mM}$ DTT and $0.02 \%(\mathrm{w} / \mathrm{v})$ sodium azide. The reaction was started by adding $37.5 \mu \mathrm{l}$ of saliva to $150 \mu \mathrm{l}$ of $1 \mathrm{mM}$ substrate solution and $1.5 \mu \mathrm{l}$ ethanol. An inhibition reaction was also performed on each sample by adding $1.5 \mu \mathrm{l}$ of a $56 \mathrm{mM}$ ethanolic solution of THL (tetrahydrolipstatin) instead of ethanol. Kinetics of the intensity of fluorescence was recorded at $37{ }^{\circ} \mathrm{C}$ (excitation filter: $355 \mathrm{~nm}$; emission filter: $460 \mathrm{~nm}$ ) using a microplate fluorometer (Victor 3-V, PerkinElmer, France). Lipolysis was calculated from the difference of fluorescence slope of each sample with and without THL and expressed in reference to a standard curve of umbelliferone. At each set of measurements, a control of the linearity and proportionality of the reaction was performed using commercial lipase (Aspergillus niger Lipase, Fluka, France).

\subsubsection{Proteolysis}

Proteolysis was determined using a Pierce Fluorescent Assay Kit (Pierce Biotechnology, Rockford, IL) following the manufacturer's instructions. This kit uses a fluorescein-labeled casein substrate which emits fluorescence upon proteolytic digestion (excitation at $494 \mathrm{~nm} / \mathrm{emission}$ at $518 \mathrm{~nm}$ ). Tryspin was used to establish a standard curve. Results were obtained as trypsin equivalent and further converted into IU.

\subsubsection{Total antioxidant status}

Total antioxidant status was determined using an ORAC Assay kit (Zen-Bio, Research Triangle Park, NC, USA). This assay uses the free radicals initiator AAPH (2,2'-azobis-2-methyl-propanimidamide, dihydrochloride). Peroxyl radicals then oxidize fluorescein with a consequent loss of fluorescence. Trolox (6-hydroxy-2,5,7,8-tetramethylchroman2-carboxylic acid), a water-soluble vitamin E analogue, serves as a standard to inhibit fluorescein decay in a dose dependent manner. Kinetics of the intensity of fluorescence was recorded at $37^{\circ} \mathrm{C}$ (excitation filter: $485 \mathrm{~nm}$; emission filter: $538 \mathrm{~nm}$ ) using a microplate fluorometer (Victor 3-V, PerkinElmer, France). The antioxidant capacity of saliva was expressed as micromolar Trolox equivalents per $\mathrm{ml}$.

\subsection{Proteome analysis}

2.4.1. 2D electrophoresis and identification of proteins of interest by MALDI-ToF-ToF

Sample preparation and 2D electrophoresis were performed following the protocol previously used for saliva and described in Mounayar 
et al. [15] with the following modifications: the protein load for each $11 \mathrm{~cm} 3-10 N L$ IEF strip was adjusted to $100 \mu \mathrm{g}$. Two strips were placed adjacently on one large second dimension gel. Strips were randomly assigned to gels. Gel images were acquired on a GS-800 densitometer (Bio-Rad) and images were analyzed using Samespots software (NonLinear Dynamics). 163 spots were detected and matched across all gels. Spot volumes were normalized within one gel and transformed into $\log$ values. Following statistical analysis, spots of interest were manually excised. Spot preparation, trypsin digestion, peptide extraction and MALDI-TOF MS and MS-MS analyses using a MALDI TOF/TOF UltrafleXtreme were performed as in Mounayar et al. [16]. For one spot in particular containing cystatin B, and based on the fact that this protein is detected in human saliva mostly as S-modified N-acetylated derivatives $[17,18], \mathrm{N}$-acetylation, glutathionylation and cysteinylation were accepted as variable modifications in order to tentatively identify the proteoform involved. The database search was performed in SwissProt restricted to human entries.

\subsubsection{SELDI-ToF MS profiling}

For SELDI-TOF analysis, $25 \mu \mathrm{l}$ of saliva were diluted with $225 \mu \mathrm{L}$ of dilution buffer ( $0.5 \mathrm{M} \mathrm{NaCl}, 0.1 \%$ Triton in PBS). The ProteinChip arrays were conditioned in the following manner: $5 \mu \mathrm{l}$ of $100 \mathrm{mM}$ copper sulfate were loaded onto the spots. After $5 \mathrm{~min}$ incubation in a wet chamber, the $\mathrm{CuSO} 4$ solution was removed and arrays were washed twice with $10 \mu \mathrm{l}$ of water. Arrays were then pre-equilibrated with $150 \mu \mathrm{L}$ of dilution buffer for $5 \mathrm{~min}$ with gentle agitation. After removing buffer, diluted samples were added and incubated for $45 \mathrm{~min}$ on a plate shaker at room temperature. The wells were washed with $200 \mu \mathrm{L}$ of dilution buffer $(2 \times 5 \mathrm{~min})$ and $200 \mu \mathrm{L}$ of dilution buffer without triton $(1 \times 5 \mathrm{~min})$, and finally briefly rinsed with water. ProteinChip arrays were air-dried. Finally, $0.8 \mu \mathrm{L}$ of saturated sinapinic acid solution was applied twice to each spot and the chips were allowed to air-dry again. Mass spectrometry analyses were performed in a PCS4000 ProteinChip reader (Bio-Rad). Two calibrations were performed. For the low mass range (LMW), data were collected between 2 and $20 \mathrm{kDa}$, with a focusing mass at $10 \mathrm{kDa}$ and a laser intensity set at 2400 . For the high mass range (HMW), the data were collected between 20 and $200 \mathrm{kDa}$, with a focusing mass at $50 \mathrm{kDa}$ and a laser intensity set at 2600. Each spectrum was the result of 530 laser shots and was externally calibrated. Spectra analysis was carried out using the ProteinChip Data manager 3.5 (Bio-Rad). Peaks with a ratio signal/noise above 3 were identified by the ProteinChip Software. In total, $74 \mathrm{~m} / \mathrm{z}$ peaks were retained and quantified in all samples.

\subsubsection{Quantification of cystatin SN by ELISA}

Cystatin SN was quantified using an Enzyme-Linked Immunosorbent Assay kit from Cusabio (Cusabio, Wuhan, China) following the manufacturer's instructions. The concentrations were obtained in $\mathrm{ng} / \mathrm{ml}$.

\subsection{Peptidome profiling by label-free MALDI-ToF}

Peptide extracts for MALDI-TOF profiling were prepared by ultrafiltration with a molecular weight cut-off of $5 \mathrm{kDa} .1 \mu \mathrm{l}$ of sample was loaded on a ground steel target. Each spot was then covered with $1 \mu \mathrm{l}$ of HCCA solution ( $3 \mathrm{mg}^{\mathrm{ml}} \mathrm{m}^{-1}$ in $50 \% \mathrm{ACN}, 2 \% \mathrm{TFA}$ ) and dried at room temperature. Four technical replicates were performed. Samples were then automatically analyzed in linear positive mode using a MALDITOF mass spectrometer (Autoflex, Bruker) in the $\mathrm{m} / \mathrm{z}$ range $0-3000$. The 330 resulting spectra were first pre-processed to retrieve from the observed signals the part related to technical noise (removal of random noise of measure, baseline subtraction, normalization). Peaks corresponding to potential markers (295 per subject) were then detected and quantified.

Following statistical analysis (described below), identification of discriminant peaks was attempted by MALDI-TOF-TOF and nanoLC-ESI
MS-MS. For MALDI-TOF-TOF, an UltrafleXtreme Bruker Daltonics mass spectrometer was used in automatic mode. Ionization was performed by irradiation of a nitrogen laser $(337 \mathrm{~nm}$ ) operating at $1 \mathrm{GHz}$ in reflector mode. Mass calibration was achieved using the peptide calibration standards from Bruker Daltonics. MS-MS spectra were interpreted with the MatrixScience MASCOT search engine against the SwissProt database. Methionine oxidation was accepted as a variable modification. Mass deviation tolerance was set at $50 \mathrm{ppm}$ in MS mode and 0.6 Da in MS/MS mode. For nanoLC-ESI MS-MS, liquid chromatography was performed on a C18 column $(15 \mathrm{~cm}, 75 \mu \mathrm{m}$ of internal diameter) with a gradient consisting of $2-80 \%$ ACN in $0.1 \%$ formic acid over $1 \mathrm{~h}$. The eluate was directed to an Orbitrap mass spectrometer (ELITE, ThermoScientific). For each full MS scan, MS-MS spectra were obtained for the 20 most abundant peaks. Raw data were processed and identification was performed using the software Proteome Discoverer 1.4, searching the SwissProt database. Methionine was accepted as a variable modification. Peptide mass tolerance and fragment mass tolerance were set at $10 \mathrm{ppm}$ and $0.6 \mathrm{Da}$, respectively.

\subsection{Metabolome analysis by ${ }^{1} H \mathrm{NMR}$}

${ }^{1} \mathrm{H}-\mathrm{NMR}$ analyses on saliva samples were performed according to the protocol described in Neyraud et al. [19]. $100 \mu \mathrm{l}$ of sample were mixed to $550 \mu$ of deuterium oxide $\left(D_{2} \mathrm{O}\right)$ containing $0.25 \mathrm{mM}$ sodium trimethylsilyl-[2,2,3,3-2 $\left.{ }^{2} \mathrm{H}_{4}\right]-1$-propionate (TSP; as a chemical shift reference at $0 \mathrm{ppm}$ ). After centrifugation (10 $\mathrm{min}$ at 5,000 $\times \mathrm{g}$ ), the supernatant was introduced in a $5 \mathrm{~mm}$ NMR tube. Spectra were obtained using a Bruker DRX-600 Advance NMR spectrometer operating at $600.13 \mathrm{MHz}$ for a ${ }^{1} \mathrm{H}$ resonance frequency and an inverse detection $5 \mathrm{~mm}{ }^{1} \mathrm{H}-{ }^{13} \mathrm{C}-{ }^{15} \mathrm{~N}$ cryoprobe attached to a cryoplatform. A total of 512 transients were acquired at $300 \mathrm{~K}$ using the Carr-Purcell-MeiboomGill (CPMG) spin-echo pulse sequence with presaturation. Spectra were data reduced using AMIX (version 3.9.11, Bruker, Germany) to integrate $0.01 \mathrm{ppm}$ wide regions corresponding to the $\delta 8.5-0.7 \mathrm{ppm}$ region. The $\delta 6.7-4.25 \mathrm{ppm}$ region, which includes water resonance, was excluded. Each integrated region was normalized to the total spectral area. A total of 536 NMR buckets were included in the data matrices. Following statistical analysis (described below), discriminant buckets were assigned to metabolites using reference spectra from a homemade and other reference databases (http://www.bmrb.wisc.edu/ metabolomics; http://www.hmdb.ca) and reports from literature.

\subsection{Overview of analyses}

Targeted analyses ( $n=42,20 \mathrm{ED} / 22 \mathrm{C}), 2 \mathrm{D}$ electrophoresis $(\mathrm{n}=26$, 9ED/17C) and confirmation of cystatin SN abundance by ELISA $(n=34$, $15 \mathrm{ED} / 19 \mathrm{C}$ ) were performed on T0 samples taken at the first sampling time.

Profiling methods were performed on samples taken at the three sampling times. The volume of saliva collected allowed performing the following analyses: ${ }^{1} \mathrm{H}$ NMR and MALDI-TOF MS analyses on $44 \mathrm{TO}$ samples, 33 T6 samples (16ED/17C) and $34 \mathrm{~T} 12$ samples (16ED/18C); SELDI-TOF profiling on 42 T0 samples (20ED/22C), 33 T6 samples (16ED/17C) and $33 \mathrm{~T} 12$ samples (16ED/17C).

\subsection{Statistics}

The difference between ED and C subjects in terms of saliva protein content, TAS, enzymatic activities and 2DE protein spot abundance was tested by Student-tests. Confirmation of under-expression of cystatin SN in ED subjects was statistically tested using a one-tailed Student-test.

For spectral data (SELDI-TOF, MALDI-TOF, ${ }^{1} \mathrm{H}$ NMR), the longitudinal effect was evaluated by testing the correlation between datasets obtained for each of the 3 sampling times. For this, RV coefficients were calculated and their significance tested. The resulting p-values were all $<0.001$, which indicates that spectra were overall not affected by the 
Table 1

Biochemical characteristics of saliva of eating difficulties patients (ED, $n=20$ ) and healthy controls $(\mathrm{C}, \mathrm{n}=22)$.

\begin{tabular}{|c|c|c|c|c|c|}
\hline & \multicolumn{2}{|l|}{ Mean } & \multicolumn{2}{|c|}{ Median } & \multirow[t]{2}{*}{ p-Value } \\
\hline & ED & C & $\mathrm{ED}$ & C & \\
\hline Protein content (mg.ml ${ }^{-1}$ ) & 0.86 & 1.05 & 0.76 & 1.00 & 0.226 \\
\hline Amylolysis (mIU.ml ${ }^{-1}$ ) & 84.53 & 117.86 & 47.39 & 81.13 & 0.146 \\
\hline Lipolysis (mIU.ml ${ }^{-1}$ ) & 0.25 & 0.22 & 0.16 & 0.19 & 0.673 \\
\hline Proteolysis (mIU.ml ${ }^{-1}$ ) & 122.38 & 22.98 & 11.12 & 7.27 & 0.075 \\
\hline TAS ( $\mu$ mol Trolox eq. $\left.\mathrm{ml}^{-1}\right)$ & 33.27 & 62.30 & 26.70 & 52.11 & $<0.001$ \\
\hline
\end{tabular}

sampling time, i.e. that the longitudinal effect over one year was limited. Nevertheless, in order to account for the possibility that some specific peaks may be affected, data were first corrected for the "sampling time effect" before retaining the median value of peak intensities over the 3 sampling times. A Surrogate Variables Analysis was then performed to select peaks discriminant between ED and C children. This method allows the estimation and incorporation of known as well as unknown sources of variability that may be confounding. Differential markers are selected based on the significance of their differential effect. Benjamini-Hochberg correction method was applied to control the False Discovery Rate (FDR) at $10 \%$.

Finally, the impact of age on abundance of the discriminant features was tested. For each discriminant variable, a linear model (abundance vs age of the subjects at $\mathrm{T} 0$ ) was adjusted and its significance tested by ANOVA.

\section{Results}

\subsection{Targeted biochemical analyses}

Protein content, lipolytic activity and amylolytic activity were not significant different between the two groups. There was a tendency $(\mathrm{p}=0.075)$ for proteolytic activity to be higher in ED patients, and they also exhibited a significant $(p<0.001)$ lower total antioxidant status (Table 1).

\subsection{Proteome analysis}

The expression level of 11 spots was significantly $(\mathrm{p}<0.05)$ different between ED and $C$ subjects, with 6 spots under-expressed and 5 overexpressed in ED subjects. Ten out of the 11 spots were successfully identified by MALDI-TOF MS-MS (Table 2). The identified proteins showed apparent molecular weights close to the theoretical ones, with two exceptions. One spot containing alpha-amylase 1 appeared at approximately $30 \mathrm{kDa}$, which indicates that the protein is truncated by proteolysis or alternative splicing. Another spot containing both the variable and constant regions of the immunoglobulin light chain kappa appeared at a molecular weight corresponding approximately to the sum of the individual regions' molecular weights, suggesting that the spot contained a full Ig kappa. Concerning cystatin B, the specific proteoform could not be identified since the tryptic peptide that would be modified (MMCGAPSATQPATAETQHIADQVR) was detected neither as unmodified nor as $\mathrm{N}$-acetylated or $\mathrm{N}$-acetylated S-modified derivatives (glutathionylated or cysteinylated). Other methods such as top-down RP-HPLC-ESI-MS would be of interest to further characterize the exact cystatin B proteoform present in the differently expressed spot, as previously reported [17]. Nevertheless, altogether, saliva of ED patients was characterized by lower abundance of cystatins (SN, B and D) and glutathione S-transferase P (GSTP). Oppositely, it contained more of two alpha-amylase 1 isoforms and zinc-alpha-2-glycoprotein (ZAG). The results on Ig kappa light chain and Ig alpha-1 chain $C$ region (the constant region of IgA1 heavy chain) can be considered together as an indication of over-expression of IgA1 in saliva of ED patients.

In SELDI-TOF profiling, 10 peaks were significantly different (FDR < $10 \%$ ) between ED and C subjects, with one peak over-expressed and nine under-expressed in ED patients (Table 3). Identification of discriminant peaks is not readily available in SELDI-TOF MS. However, based on the known molecular weight of cystatin SN (14,312 Da for the mature chain), and the convergence with $2 \mathrm{D}$ results, it is most likely that the most discriminant peak corresponds to this protein. In addition, double-charged ions are occasionally generated and detected by SELDI-TOF MS [20]. The peak at $\mathrm{m} / \mathrm{z} 7155$ could therefore also correspond to the same compound that would be detected as a doublecharged ion.

Because of this common finding between the two techniques, cystatin SN under-expression in saliva of ED patients was verified by ELISA. Saliva of ED and C subjects contained 119 and $225 \mathrm{ng} \cdot \mathrm{ml}^{-1}$ of cystatin SN, respectively, and the difference between the two groups was highly significant $(\mathrm{p}=0.001)$. Fig. 1 illustrates the findings related to cystatin SN expression in saliva of ED and C subjects.

\subsection{Peptidome analysis}

The abundance of 6 peaks was significantly (FDR $<10 \%$ ) different between ED and $C$ subjects, with 2 peaks under-expressed and 4 overexpressed in ED subjects (Table 3). Examination of MALDI-TOF spectra revealed that the peaks at $\mathrm{m} / \mathrm{z} 2112.88,2630.21,2658.10$ were difficult to isolate for identification by MALDI TOF-TOF due to the presence of

Table 2

Details of mass spectrometry results (MALDI-TOF or MALDI TOF-TOF) for proteins differently expressed between eating difficulties subjects (ED) and healthy controls.

\begin{tabular}{|c|c|c|c|c|c|c|c|c|c|}
\hline Protein & $\begin{array}{l}\text { Fold- } \\
\text { change }\end{array}$ & $\mathrm{p}$ Value & $\begin{array}{l}\text { SwissProt } \\
\text { reference }\end{array}$ & $\begin{array}{l}\text { Theoretical }{ }^{\mathrm{a}} / \text { estimated } \\
\text { MW (kDa) }\end{array}$ & $\begin{array}{l}\mathrm{N}^{\circ} \text { of peptides } \\
\text { MS mode }\end{array}$ & $\begin{array}{l}\text { Sequence } \\
\text { coverage }\end{array}$ & $\begin{array}{l}\text { Mascot score }{ }^{\mathrm{b}} \\
\text { MS mode }\end{array}$ & $\begin{array}{l}\mathrm{N}^{\circ} \text { of peptides identified } \\
\text { MS/MS mode }\end{array}$ & $\begin{array}{l}\text { Mascot score } \\
\text { MS/MS mode }\end{array}$ \\
\hline \multicolumn{10}{|c|}{ Under-expressed in ED patients } \\
\hline Cystatin SN & 1.9 & $<0.001$ & P01037 & $14.3 / 14$ & 10 & 68.8 & 168.0 & 1 & 72.6 \\
\hline Cystatin D & 2.5 & 0.003 & P28325 & $13.9 / 13$ & / & / & / & 2 & 152.9 \\
\hline Cystatin B & 1.5 & 0.006 & P04080 & $11.1 / 11$ & 6 & 64.3 & 100.0 & 2 & 188.5 \\
\hline n.i. & 2.2 & 0.022 & / & / & / & / & / & / & / \\
\hline Cystatin D & 1.8 & 0.030 & P28325 & $13.9 / 13$ & / & / & / & 2 & 178.8 \\
\hline Glutathione-S-transferase P & 1.7 & 0.046 & P09211 & $23.2 / 23$ & 5 & 35.7 & 87.3 & 2 & 102.5 \\
\hline \multicolumn{10}{|c|}{ Over-expressed in ED patients } \\
\hline Alpha-amylase 1 & 1.8 & 0.002 & P04745 & $55.9 / 30$ & 9 & 23.5 & 110.0 & 2 & 101.5 \\
\hline Ig alpha- 1 chain $C$ region & 1.9 & 0.025 & P01876 & $37.7 / 35$ & 8 & 35.4 & 125.0 & 2 & 174.6 \\
\hline Zinc-alpha-2-glycoprotein & 1.7 & 0.027 & P25311 & $34.3 / 32$ & 12 & 48.3 & 173.0 & 2 & 66.4 \\
\hline Ig kappa chain V-II region TEW & 1.5 & 0.029 & P01617 & $12.1 / 27$ & / & / & / & 2 & 78.6 \\
\hline Ig kappa chain $C$ region & & & P01834 & $11.6 / 27$ & 5 & 82.1 & 91.0 & 2 & 110.0 \\
\hline Alpha-amylase 1 & 1.6 & 0.030 & P04745 & $55.9 / 56$ & 25 & 54.4 & 237.0 & 2 & 174.3 \\
\hline
\end{tabular}

\footnotetext{
a The theoretical molecular weight reported is that of the mature chain.
}

b In MS mode, the identification is significant if Mascot score is $>56$.

c In MS/MS mode, the identification is significant if Mascot score is $>50$. 
Table 3

Mass spectrometry peaks and ${ }^{1} \mathrm{H}$ NMR buckets differently represented between eating difficulties subjects (ED) and healthy controls.

\begin{tabular}{llll}
\hline Method & $\begin{array}{l}\mathrm{m} / \mathrm{z}(\mathrm{SELDI}), \mathrm{M}+\mathrm{H}^{+} \text {(MALDI) } \\
\text { or chemical shift in ppm (NMR) }\end{array}$ & $\begin{array}{l}\text { Status in ED } \\
\text { patients }^{\mathrm{a}}\end{array}$ & $\begin{array}{l}\text { Adjusted } \\
\text { p-Values }\end{array}$ \\
\hline SELDI TOF MS & 2107 & - & 0.078 \\
& 2612 & + & 0.057 \\
& 3289 & - & 0.024 \\
& 7155 & - & 0.057 \\
& 11,732 & - & 0.095 \\
& 14,306 & - & 0.024 \\
& 19,091 & - & 0.056 \\
& 28,646 & - & 0.037 \\
MALDI-TOF MS & 1033.729 & - & 0.078 \\
& 43,220 & - & 0.057 \\
& 1161.63 & + & 0.053 \\
1353.73 & - & 0.081 \\
${ }^{1} \mathrm{H}$ NMR & 2112.88 & - & 0.078 \\
& 2630.21 & + & 0.053 \\
& 2658.10 & + & 0.069 \\
& $1.335,1.325$ & + & 0.053 \\
$1.485,1.475$ & + & 0.067 \\
& 2.735 & + & 0.042 \\
3.495 & - & 0.067 \\
3.945 & - & 0.007 \\
$4.125,4.115$ & - & 0.013 \\
7.915 & - & 0.095 \\
& & - & 0.036 \\
\hline
\end{tabular}

a The "+" and "-" signs indicate that the compound is respectively over-represented or under-represented in ED patients.

several overlapping species. Identification was attempted on the three other peaks, and the peak at $\mathrm{m} / \mathrm{z} 1033.57$ was identified as a fragment of salivary acidic proline-rich phosphoprotein $1 / 2$ (accession number P02810, peptide sequence GPPQQGGHQQ). Fig. 2 illustrates the findings related to this peptide. Using nanoLC ESI MS-MS, an additional peak at $\mathrm{m} / \mathrm{z} 1161.63$ was identified. It corresponded to a fragment of submaxillary gland androgen-regulated protein (accession number P02814, peptide sequence GRIPPPPPAPY).

\subsection{Metabolome analysis}

10 buckets were significantly (FDR $<10 \%$ ) different in abundance between the two groups (Table 3). These corresponded to 5 metabolites: lactate $(1.335,1.325,4.125,4.115)$ and alanine $(1.485,1.475)$ were over-represented in saliva of ED patients while dimethylamine (2.735), galactose $(3.495,3.945)$ and histidine $(7.915)$ were under-represented in the same patients.

\subsection{Impact of age on abundance of discriminant variables}

Globally, the total antioxidant status was not affected by age. Similarly, none of the discriminant peaks, buckets or spots were correlated with age of the children at the time of inclusion.

\section{Discussion}

The present study aimed at investigating whether eating difficulties developed consecutively to artificial nutrition in the first months of life had consequences on saliva profiles. The hypothesis tested was that the common trait to all patients, namely the reduced intake of food through the oral route, had an impact sufficiently important to be detected in spite of other sources of variability (age, medical condition etc.). Overall, we found that saliva of ED patients showed indeed distinctive characteristics.

In this study, the impact of age on salivary profiles appeared rather limited at two levels: for a given subject over one year, and at the group level in the approximate age range $2-11$ year-old. One should note however that the purpose of this study was not to explore age
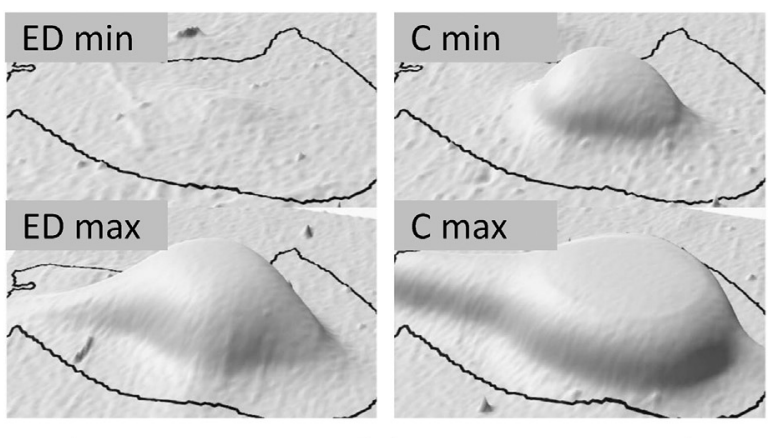

\begin{tabular}{l} 
A \\
\hline B
\end{tabular}
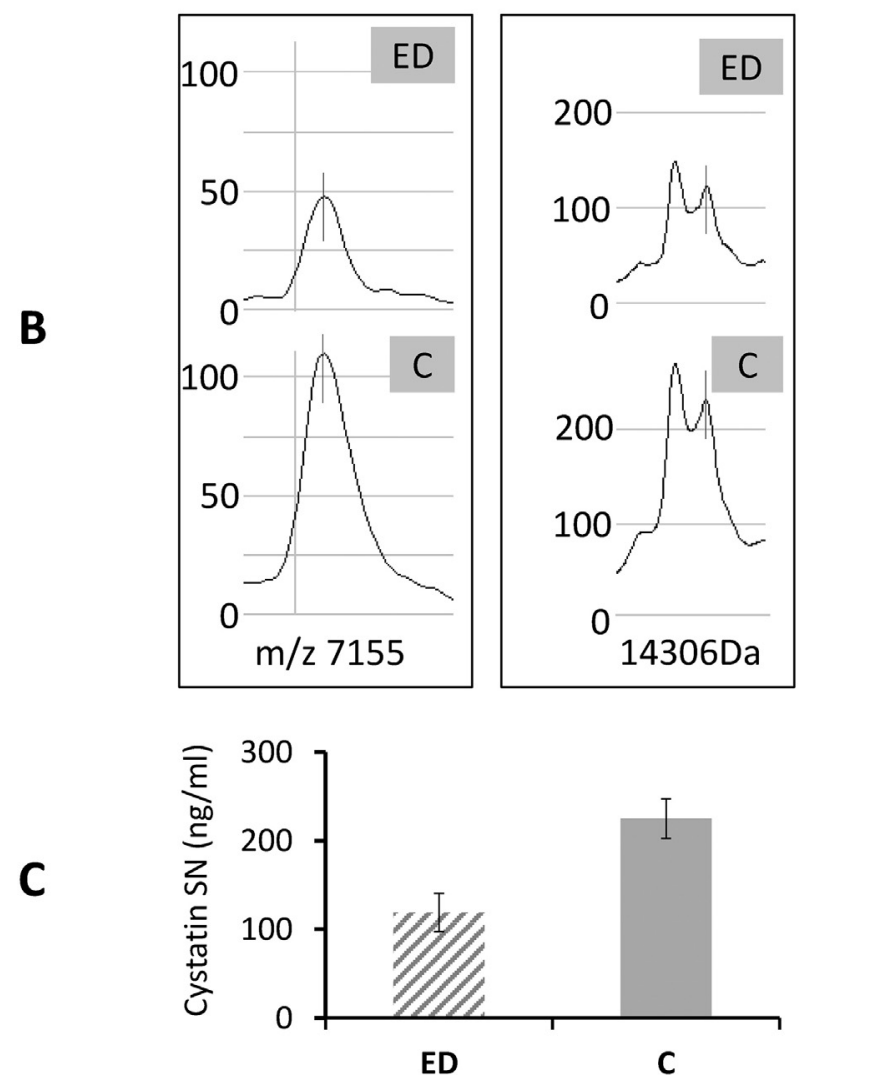

Fig. 1. Under-expression of cystatin SN in eating difficulties (ED) patients compared to healthy controls (C), illustrated by: A) volume representation of the two-dimensional electrophoresis spot containing cystatin SN. For each group (ED, C), the minimal and maximal values are represented. B) SELDI peaks putatively identified as corresponding to cystatin SN as double charged ( $\mathrm{m} / \mathrm{z} 7155)$ and single-charged ( $\mathrm{m} / \mathrm{z} 14306)$ ions; and C) quantification of cystatin SN by ELISA (mean \pm SEM).

variations, elsewhere described by other authors [21], and therefore we tested the age effect only on discriminant variables. The fact that cystatin SN abundance in particular is not significantly affected by age of the subjects contrasts with findings of another study [21] but may be explained by the lower number of subjects here.

From a mere profiling point of view, it is interesting to note that the three spectral methods allowed discriminating between the two groups. The difference between saliva of ED and C subjects was therefore related to all types of constituents measured: proteins, peptides and metabolites. Profiling methods have been previously used to discriminate saliva of patients and healthy subjects. For example, SELDITOF MS was used to search for biomarkers of Sjögren's syndrome [22] or of oral squamous cell carcinoma [23]. ${ }^{1} \mathrm{H}$ NMR proved useful to identify different metabolite signatures in children with and without caries [24]. As to MALDI-TOF profiling, it was combined to magnetic bead sample treatment and allowed to identify markers of periodontal disease in subjects with or without orthodontic treatment [25]. In all 


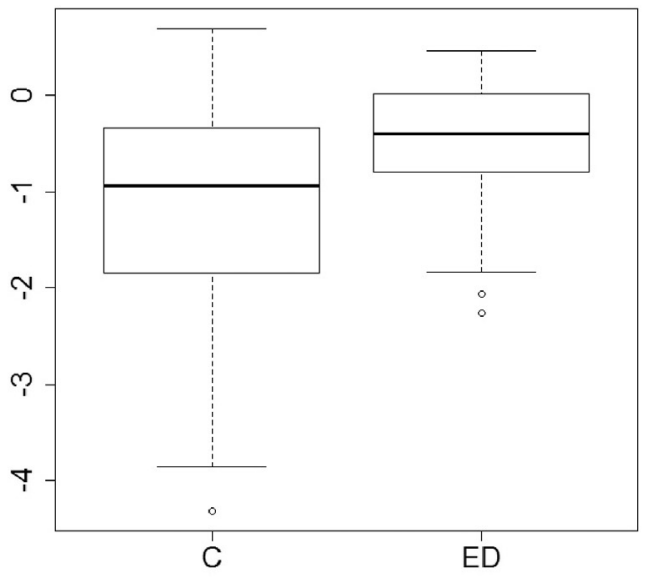

B

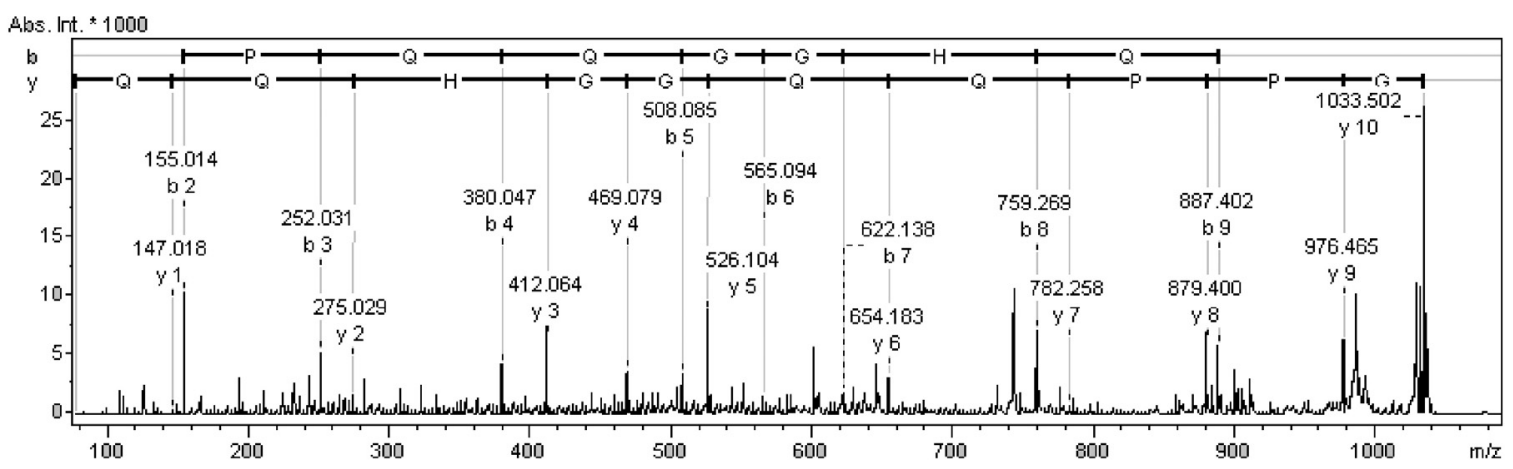

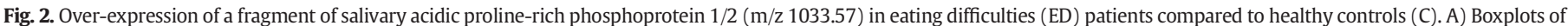
the log-intensities of the peak after preprocessing, for ED and C subjects. B) MS-MS spectrum of the peptide.

these studies, the patients were carefully selected based on homogenous clinical criteria, and gross medical confounding conditions were excluded. In the present study, what the patients had in common at the time of sampling was a proportion of energy intake received by the oral route at or below $50 \%$, but they were otherwise quite diverse with regards to their medications, and initial pathology. The fact that it was still possible to discriminate ED and $C$ subjects suggests a major role of diet and/or food intake through the oral route to shape the compositional pattern of saliva.

The impact of diet on saliva composition of human subjects has been reported on several occasions. At a population level for example, individuals from population with high-starch diets have more copies of the salivary amylase gene AMY1 than those from populations with low-starch diets [26]. At an individual level, shift from a mixed to a lactovegetarian diet modified some salivary characteristics such as its sodium content or buffering capacity [27], while change from a milkbased to a diversified diet in infants had an impact both on salivary protein [28] and peptide [29] profiles. Another study compared two groups of subjects, controls or subjected to a dietary intervention from infancy, who were the followed for up to 16 years of age. Although some dietary differences persisted between the two groups, in particular a higher fiber intake in the intervention group, the analyzed salivary constituents (calcium, phosphate, total proteins) did not differ between the groups. However, flow rate and buffering capacity were modified [30]. There are some differences between the studies of Laine et al. and the present study where we also compared two different groups. First, we used untargeted and highly resolutive methods which allowed discriminating the groups, and which identified molecules which may not have been otherwise tested. Second, our ED and C groups were clearly contrasted in terms of diet. Rather than differences in energy and nutriment intake, where potential deficits were compensated in ED children by artificial nutrition, the specificity of ED children was rather a reduced stimulation of the oral cavity by food intake, and most likely lower diversity in their food repertoire. Altogether, this suggests that saliva plasticity induced by usual diet is governed partly by mechanisms linking local oral stimulation to saliva secretion.

Looking now at the biological information brought about by the discriminating molecules and biochemical characteristics, a first prominent finding is that saliva of ED children had a lower total antioxidant status (TAS). Many compounds, such as albumin, transferrin or uric acid contribute to the antioxidant properties of saliva [31], but of special interest here are glutathione-S-transferases which can suppress free radicals formation. Under-expression of GSTP in ED patients is therefore probably one element contributing to this reduced TAS. Salivary antioxidant properties have been previously linked to weight status, with higher TAS in obese vs normal weight subjects [32], but the article does not discuss the possible link with food intake. Regarding tube feeding, it was shown to be associated with reduced acid uric in elderly subjects [33] and in patients with neurological disorders [34] although TAS measured by the FRAP method was not modified in the second case. Mastication of foods has been suggested to be a source of oxidative reactions $[35,36]$, which may increase salivary TAS as a feedback mechanism. This would then be consistent with the finding that ED subjects with reduced oral intake of food show lower TAS.

The second type of information relates broadly to proteolytic events in the oral cavity of ED children. ED children tend to have a higher saliva proteolytic activity, and also exhibit lower levels of the cysteine protease inhibitors cystatins B, D and SN, the latter finding confirmed by immunological measurement. However, no large differences were observable on free amino-acids detected by ${ }^{1} \mathrm{H}$ NMR. Similarly, relatively few differences were observed in peptidome profiles although the majority of peptides consistently detected on MALDI-TOF spectra of whole saliva are fragments of salivary proteins [29,37]. Finally, apart from one possible fragment of amylase, 2D electrophoretic profiles did 
not reveal extensive cleavage of salivary proteins in ED children. Therefore, rather than enhanced active proteolysis, the results may be interpreted as a higher proteolytic potential (towards exogeneous substrates for example) and a lower capacity to prevent any potential excessive proteolysis. In the oral cavity, proteolysis may be due to host-derived proteases but also to exogenous proteases of bacterial or food origin. As an illustration, it was shown that cystatin SN was present at higher levels in saliva of infants who had started receiving solid foods (thereby exposed to cysteine proteases of plant origin) compared to those still on a milk-only diet [29]. Based on the poor inhibition of endogenous cysteine proteases such as cathepsins, Dickinson [38] suggested that one of the primary functions of salivary cystatins in primates is to protect the oral cavity from dietary and environmental cysteine proteases. Again, this is consistent with the reduced intake of food through the oral route in ED children.

Two other identified discriminant molecules may relate to the oral or intestinal microbial ecology. Thus, IgA1 (in its dimeric form sIgA1) is part of the first line of defense against pathogens in the oral cavity [39]. However, targeted microbial assessments would be necessary to evaluate the ecological quality of oral flora in ED patients. Concerning dimethylamine (DMA), it is one of the most commonly occurring nitrosatable secondary amines in saliva [40]. DMA can have an endogenous origin when formed from dietary choline, in a reaction catalyzed by enzymes of gut bacteria [41,42]. Neo formed DMA is then absorbed and secreted in various body fluids including saliva [43]. Therefore, its lower abundance in the ED group could result from alterations of the gut microbiota consecutively to the initial pathologies of these subjects. Indeed, it has been reported that hospitalization in neonatal intensive care units (e.g. extremely low-birthweight infants) which is characterized in particular by parenteral nutrition and delayed oral feeding, seems to affect the composition of the intestinal microbiota [44].

Finally, although this is not related to a biological function as such, it should be pointed out that several of the identified markers in ED patients have been previously identified as markers of sensory performance, taste sensitivity and acceptance. For example, glutathione-Stransferases have been immunodetected in rat taste bud cells and the authors proposed that these may aid in maintaining the cellular homeostasis required for proper chemoreceptive function [45]. Underexpression of GSTP in ED patients would therefore be associated to a lesser performance in chemosensory perception. In contrast, and looking now at salivary profiles rather than at single proteins, the saliva of adult subjects hypersensitive to the bitter taste of caffeine was characterized by higher abundance of IgA, lower levels of cystatin SN and a tendency for higher proteolytic activity [46], which corresponds to the findings in ED patients. In three-month-old infants rejecting bitterness (i.e. most likely hypersensitive to this taste), salivary cystatins were under-expressed while two bands containing ZAG were more abundant [14], which is again consistent with the present results. ZAG was also found to be over-expressed in subjects hypersensitive to the taste of oleic acid [16]. Altogether, this shows that the salivary profiles of ED patients were partly comparable to those of subjects with enhanced gustatory sensitivity. Whether this is a factor contributing to the eating difficulties developed by children after prolonged tube feeding is not known but the topic deserves further attention.

\section{Author contributions}

The manuscript was written through contributions of all authors. All authors have given approval to the final version of the manuscript.

\section{Funding sources}

This study was funded by the French National Research Agency (grant ANR-10-ALIA-001 ORALISENS).

\section{Conflict of interest}

The authors declare no competing financial interest.

\section{Transparency document}

The Transparency document associated with this article can be found, in the version.

\section{References}

[1] E.S. Ross, J.V. Browne, Developmental progression of feeding skills: an approach to supporting feeding in preterm infants, Semin. Neonatol. 7 (2002) 469-475.

[2] C. Senez, J.M. Guys, J. Mancini, A.P. Paredes, G. Lena, M. Choux, Weaning children from tube to oral feeding, Childs Nerv. Syst. 12 (1996) 590-594.

[3] P. Dodrill, S. McMahon, E. Ward, K. Weir, T. Donovan, B. Riddle, Long-term oral sensitivity and feeding skills of low-risk pre-term infants, Early Hum. Dev. 76 (2004) 23-37.

[4] S. Bazyk, Factors associated with the transition to oral-feeding in infants fed by nasogastric tubes, Am. J. Occup. Ther. 44 (1990) 1070-1078.

[5] C. Dinnella, A. Recchia, G. Fia, M. Bertuccioli, E. Monteleone, Saliva characteristics and individual sensitivity to phenolic astringent stimuli, Chem. Senses 34 (2009) 295-304.

[6] E. Neyraud, C.I. Heinzerling, J.H.F. Bult, C. Mesmin, E. Dransfield, Effects of different tastants on parotid saliva flow and composition, Chemosens. Percept. 2 (2009) $108-116$.

[7] N.A. Hodson, R.W.A. Linden, The effect of monosodium glutamate on parotid salivary flow in comparison to the response to representatives of the other four basic tastes, Physiol. Behav. 89 (2006) 711-717.

[8] E. Neyraud, T. Sayd, M. Morzel, E. Dransfield, Proteomic analysis of human whole and parotid salivas following stimulation by different tastes, J. Proteome Res. 5 (2006) 2474-2480.

[9] M. Quintana, O. Palicki, G. Lucchi, P. Ducoroy, C. Chambon, C. Salles, et al., Short-term modification of human salivary proteome induced by two bitter tastants, urea and quinine, Chemosens. Percept. 2 (2009) 133-142.

[10] C. Dinnella, A. Recchia, S. Vincenzi, H. Tuorila, E. Monteleone, Temporary modification of salivary protein profile and individual responses to repeated phenolic astringent stimuli, Chem. Senses 35 (2010) 75-85.

[11] K. Lorenz, M. Bader, A. Klaus, W. Weiss, A. Gorg, T. Hofmann, Orosensory stimulation effects on human saliva proteome, J. Agric. Food Chem. 59 (2011) 10219-10231.

[12] C. Dawes, Effects of diet on salivary secretion and composition, J. Dent. Res. 49 (1970) 1263-1272.

[13] E. Neyraud, O. Palicki, C. Schwartz, S. Nicklaus, G. Feron, Variability of human saliva composition: possible relationships with fat perception and liking, Arch. Oral Biol. 57 (2012) 556-566.

[14] M. Morzel, C. Chabanet, C. Schwartz, G. Lucchi, P. Ducoroy, S. Nicklaus, Salivary protein profiles are linked to bitter taste acceptance in infants, Eur. J. Pediatr. 173 (2014) 575-582.

[15] R. Mounayar, M. Morzel, H. Brignot, M. Tremblay-Franco, C. Canlet, G. Lucchi, et al., Nutri-metabolomics applied to taste perception phenotype: human subjects with high and low sensitivity to taste of fat differ in salivary response to oleic acid, Omics J. Integr. Biol. 18 (2014) 666-672.

[16] R. Mounayar, M. Morzel, H. Brignot, M. Tremblay-Franco, C. Canlet, G. Lucchi, et al., Salivary markers of taste sensitivity to oleic acid: a combined proteomics and metabolomics approach, Metabolomics 10 (2014) 688-696.

[17] T. Cabras, B. Manconi, F. Iavarone, C. Fanali, S. Nemolato, A. Fiorita, et al., RP-HPLCESI-MS evidenced that salivary cystatin B is detectable in adult human whole saliva mostly as S-modified derivatives: S-glutathionyl, S-cysteinyl and S-S 2-mer, J. Proteome 75 (2012) 908-913.

[18] F. lavarone, T. Cabras, E. Pisano, M.T. Sanna, S. Nemolato, G. Vento, et al., Top-down HPLC-ESI-MS detection of S-glutathionylated and S-cysteinylated derivatives of cystatin B and Its 1-53 and 54-98 fragments in whole saliva of human preterm newborns, J. Proteome Res. 12 (2013) 917-926.

[19] E. Neyraud, M. Tremblay-Franco, S. Gregoire, O. Berdeaux, C. Canlet, Relationships between the metabolome and the fatty acid composition of human saliva; effects of stimulation, Metabolomics 9 (2013) 213-222.

[20] S. Schaub, J. Wilkins, T. Weiler, K. Sangster, D. Rush, P. Nickerson, Urine protein profiling with surface-enhanced laser-desorption/ionization time-of-flight mass spectrometry, Kidney Int. 65 (2004) 323-332.

[21] I. Messana, T. Cabras, F. Iavarone, B. Manconi, L.L. Huang, C. Martelli, et al., Chronoproteomics of human saliva: variations of the salivary proteome during human development, J. Proteome Res. 14 (2015) 1666-1677.

[22] O.H. Ryu, J.C. Atkinson, G.T. Hoehn, G.G. Illei, T.C. Hart, Identification of parotid salivary biomarkers in Sjogren's syndrome by surface-enhanced laser desorption/ ionization time-of-flight mass spectrometry and two-dimensional difference gel electrophoresis, Rheumatology 45 (2006) 1077-1086.

[23] S. Shintani, H. Hamakawa, Y. Ueyama, M. Hatori, T. Toyoshima, Identification of a truncated cystatin SA-I as a saliva biomarker for oral squamous cell carcinoma using the SELDI ProteinChip platform, Int. J. Oral Maxillofac. Surg. 39 (2010) 68-74.

[24] T.K.S. Fidalgo, L.B. Freitas-Fernandes, R. Angeli, A.M.S. Muniz, E. Gonsalves, R. Santos, et al., Salivary metabolite signatures of children with and without dental caries lesions, Metabolomics 9 (2013) 657-666. 
[25] J. Zhang, S. Zhou, R. Li, T. Cao, H. Zheng, X. Wang, et al., Magnetic bead-based salivary peptidome profiling for periodontal-orthodontic treatment, Proteome Sci. (2012) 10.

[26] G.H. Perry, N.J. Dominy, K.G. Claw, A.S. Lee, H. Fiegler, R. Redon, et al., Diet and the evolution of human amylase gene copy number variation, Nat. Genet. 39 (2007) 1256-1260.

[27] G. Johansson, D. Birkhed, Effect of a long-term change from a mixed to a lactovegetarian diet on human saliva, Arch. Oral Biol 39 (1994) 283-288.

[28] M. Morzel, O. Palicki, C. Chabanet, G. Lucchi, P. Ducoroy, C. Chambon, et al., Saliva electrophoretic protein profiles in infants: changes with age and impact of teeth eruption and diet transition, Arch. Oral Biol. 56 (2011) 634-642.

[29] M. Morzel, A. Jeannin, G. Lucchi, C. Truntzer, D. Pecqueur, S. Nicklaus, et al., Human infant saliva peptidome is modified with age and diet transition, J. Proteome 75 (2012) 3665-3673.

[30] M.A. Laine, M. Tolvanen, K. Pienihakkinen, E. Soderling, H. Niinikoski, O. Simell, et al., The effect of dietary intervention on paraffin-stimulated saliva and dental health of children participating in a randomized controlled trial, Arch. Oral Biol. 59 (2014) 217-225.

[31] M. Battino, M.S. Ferreiro, I. Gallardo, H.N. Newman, P. Bullon, The antioxidant capacity of saliva, J. Clin. Periodontol. 29 (2002) 189-194.

[32] P. Piombino, A. Genovese, S. Esposito, L. Moio, P.P. Cutolo, A. Chambery, et al., Saliva from obese individuals suppresses the release of aroma compounds from wine, PLoS One (2014) 9

[33] A. Leibovitz, R. Nagler, G. Plotnikov, B. Habot, R. Segal, Biochemical, immunological and enzymatic components of saliva in prolonged naso-gastric-fed elderly patients, Aging Clin. Exp. Res. 16 (2004) 457-460.

[34] A.S. Cunha-Correia, A. Hernandes Neto, A.F. Pereira, S.M.H. Coelho Avila Aguiar, A.C. de Melo Stevanato Nakamune, Enteral nutrition feeding alters antioxidant activity in unstimulated whole saliva composition of patients with neurological disorders, Res. Dev. Disabil. 35 (2014) 1209-1215.
[35] J. Terao, A. Nagao, Antioxidative effect of human saliva on lipid peroxidation, Agric Biol. Chem. 55 (1991) 869-872.

[36] K.F. Pirker, T.G. Reichenauer, B.A. Goodman, K. Stolze, Identification of oxidative processes during simulated mastication of uncooked foods using electron paramagnetic resonance spectroscopy, Anal. Chim. Acta 520 (2004) 69-77.

[37] A. Caseiro, R. Ferreira, A. Padrao, C. Quintaneiro, A. Pereira, R. Marinheiro, et al. Salivary proteome and peptidome profiling in type 1 diabetes mellitus using a quantitative approach, J. Proteome Res. 12 (2013) 1700-1709.

[38] D.P. Dickinson, Salivary (SD-type) cystatins: over one billion years in the makingbut to what purpose? Crit. Rev. Oral Biol. Med. 13 (2002) 485-508.

[39] H. Marcotte, M.C. Lavoie, Oral microbial ecology and the role of salivary immunoglobulin A, Microbiol. Mol. Biol. Rev. 62 (1998) 71-109.

[40] A.R. Tricker, B. Pfundstein, T. Kalble, R. Preussmann, Secondary amine precursors to nitrosamines in human saliva, gastric-juice, blood, urine and feces, Carcinogenesis 13 (1992) 563-568.

[41] S.H. Zeisel, K.A. Dacosta, J.G. Fox, Endogenous formation of dimethylamine, Biochem J. 232 (1985) 403-408.

[42] S.H. Zeisel, J.S. Wishnok, J.K. Blusztajn, Formation of methylamines from ingested choline and lecithin, J. Pharmacol. Exp. Ther. 225 (1983) 320-324.

[43] M. Hill, 18 - gut flora and cancer in humans and laboratory animals, in: I.R. Rowland (Ed.), Role of the Gut Flora in Toxicity and Cancer, Academic Press 1988 pp. 461-502.

[44] S. Fanaro, R. Chierici, P. Guerrini, V. Vigi, Intestinal microflora in early infancy: composition and development, Acta Paediatr. 92 (2003) 48-55.

[45] T. Nishino, H. Kudo, Y. Doi, M. Maeda, K. Hamasaki, M. Morita, et al., Immunocytochemistry of glutathione S-transferase in taste bud cells of rat circumvallate and foliate papillae, Chem. Senses 26 (2001) 179-188.

[46] M. Dsamou, O. Palicki, C. Septier, C. Chabanet, G. Lucchi, P. Ducoroy, et al., Salivary protein profiles and sensitivity to the bitter taste of caffeine, Chem. Senses 37 (2012) 87-95. 